\title{
Damage Assessment of Two-Way Bending RC Slabs Subjected to Blast Loadings
}

\author{
Haokai Jia, ${ }^{1}$ Ling Yu, ${ }^{1,2}$ and Guiying $\mathrm{Wu}^{2,3}$ \\ ${ }^{1}$ Department of Mechanics and Civil Engineering, Jinan University, Guangzhou 510632, China \\ ${ }^{2}$ MOE Key Laboratory of Disaster Forecast and Control in Engineering, Jinan University, Guangzhou 510632, China \\ ${ }^{3}$ College of Mechanics, Taiyuan University of Technology, Taiyuan, Shanxi 030024, China \\ Correspondence should be addressed to Ling Yu; lyu1997@163.com
}

Received 8 January 2014; Accepted 2 June 2014; Published 8 July 2014

Academic Editor: Ying Lei

Copyright (C) 2014 Haokai Jia et al. This is an open access article distributed under the Creative Commons Attribution License, which permits unrestricted use, distribution, and reproduction in any medium, provided the original work is properly cited.

\begin{abstract}
Terrorist attacks on vulnerable structures and their individual structural members may cause considerable damage and loss of life. However, the research work on response and damage analysis of single structural components, for example, a slab to blast loadings, is limited in the literature and this is necessary for assessing its vulnerability. This study investigates the blast response and damage assessment of a two-way bending reinforced concrete (RC) slab subjected to blast loadings. Numerical modeling and analysis are carried out using the commercial finite element code LS-DYNA 971. A damage assessment criterion for the two-way bending RC slab is defined based on the original and residual uniformly distributed load-carrying capacity. Parametric studies are carried out to investigate the effects of explosive weight and explosive position on the damage mode of the two-way RC slab. Some design parameters, such as the boundary conditions and the negative reinforcement steel bar length, are also discussed. The illustrated results show that the proposed criterion can apply to all failure modes. The damage assessment results are more accurate than the ones due to the conventional deformation criterion.
\end{abstract}

\section{Introduction}

Over the last two decades, increased terrorist attacks on civilian and military structures have drawn considerably more attention to the vulnerability and sustainability of structures and their individual structural members when subjected to blast loadings [1]. However, the research work on response and damage analysis of single structural components, for example, a slab to blast loadings, is limited in the literature and this is necessary for assessing its vulnerability. Some investigations have been conducted mainly for one-way slab based on one of the three methods: (1) theoretical analysis by equivalent single degree of freedom (SDOF) systems, (2) finite element analysis methods, and (3) the field measurements. Two loosely coupled SDOF systems were used to analyze the failure model of one-way bending RC slab subjected to blast loadings, and the results showed that the failure mode of slab tends to be direct failure [2]. Jones et al. developed one finite difference program to simulate the dynamic response of a simply supported RC slab under blast loadings, and the deformation of slab was due to the duration time and peak value of blast loadings [3]. However the SDOF model cannot forecast the localized damage element of the structure; more and more studies are based on commercial software, such as LS-DYNA, AUTODYN, and ABAQUS. Xu and Lu used LS-DYNA set up a three-dimensional RC plate to simulate the concrete material spallation under blast loadings [4]. Zhou et al. used a dynamic plastic model with the software AUTODYN and found that the erosion technique can be used to evaluate concrete spall together with the damage scalar $[5,6]$. Tai et al. used the erosion technique to analyze dynamic response of RC slab under the air blast loadings, and the results clearly showed the damage modes by the software LS-DYNA [7].

At the same time, the experiments of RC slab subjected to blast loadings were conducted by some researchers. Wu et al. have designed series of experiments of unretrofitted and retrofitted $\mathrm{RC}$ slabs under blast loadings to find the rule of fragment size and shape [8]. Schenker et al. illustrated the dynamic responses of unprotected and protected RC slabs 
subjected to blast loadings and compared the results with numerical simulation by MSC Software/Dytran [9]. Chung and Nurick analyzed the response of quadrangular stiffened plates under explosion by experiments and numerical simulation $[10,11]$. Wang et al. have performed blast tests and numerical simulation, respectively, to investigate the damage modes of one-way square RC slab subjected to closing blast loadings $[12,13]$. They defined the damage degree of the slab with the support rotation. Silva and Lu proposed a step-bystep method for measuring the damage degree level of RC slabs under explosion by experiments [14].

However the above studies focused on the dynamic responses and the failure models of the RC slab subjected to blast loadings. In references [12-14] the damage degree assessment was defined with the deformation of slabs as the support rotation, but it was not satisfied to all failure modes and it could be used for closing blast loads. Shi et al. [15] and Wu et al. [16] used the residual axial load-carrying capacity and axial compression capacity to assess the damage degree of RC columns subjected to blast loadings, and they concluded that the assessment contrition can be applied to all failure modes of columns, but they did not report if it is suitable for the other individual structural members, for example, the slabs.

Based on the residual uniformly distributed load-carry capacity, an assessment criterion is proposed for evaluating the damage of a two-way bending RC slab subjected to blast loadings in this study. It is defined with the decrease range of load-carry capacity. Numerical analysis and damage assessment are carried out by using the commercial finite element code LS-DYNA 971. The effects of explosive weight and position on the damage situation are studied. Some design parameters, such as the boundary conditions and the negative reinforcement steel bar length, are discussed as well. The illustrated results show that the criterion can evaluate the damage more accurately and it can be applied to all failure modes of structures.

\section{Geometry Model and Material Properties}

2.1. Geometrical Modeling. The most acceptable modeling methods of RC structures are the smeared model, embedded model, and discrete model [17]. It was stated in [17] that, for the dynamic response of structural components, the discrete model was the best method. In a discrete model, the concrete element and steel bar element are treated as different elements. A one-dimensional slide contact is added between the concrete and reinforcement elements to simulate the longitudinal shear behavior, and the differences in two material mechanical properties can be shown clearly when the blast loadings affect the structure.

The mechanical behaviors of the slab depend on the aspect ratio of length to width. When the aspect ratio is greater than 3, the slab can be deemed as a one-direction bending type structure, for example, a beam. When the aspect ratio is less than 3 , the mechanical behavior of the slab is twoway bending. The one-way bending slabs are used mostly in corridor part, and the two-way bending slabs are used in the important components of structures, such as floors and walls.

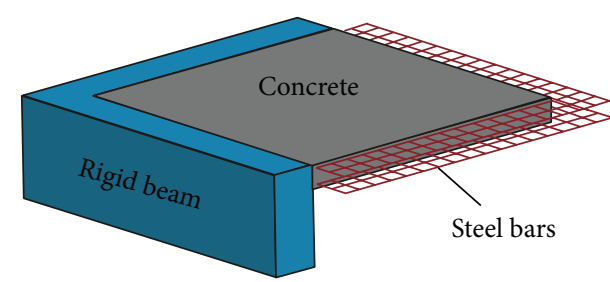

FIgURE 1: Numerical model of RC two-way bending slabs in a quarter form.

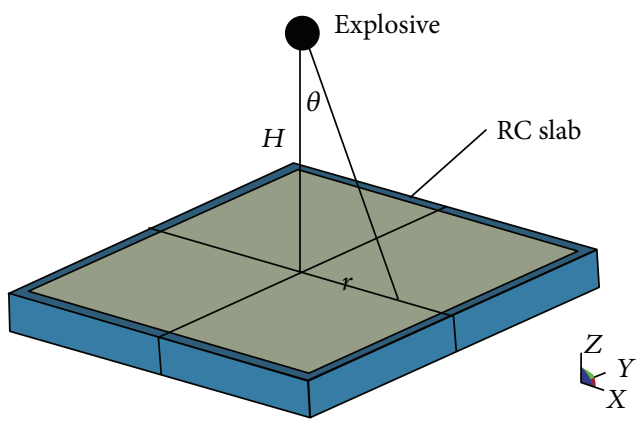

FIgURE 2: Calculating diagram of RC slab under explosion.

In this study, a square RC slab model is established. The clear dimension of the slab is $B \times L \times t=3000 \mathrm{~mm} \times 3000 \mathrm{~mm}$ $\times 120 \mathrm{~mm}$, where $B$ is the slab span length in $x$ direction, $L$ is the slab width in $y$ direction, and $t$ is the slab thickness in $z$ direction, respectively. The blast loadings are applied to slab in $z$ direction. So the aspect ratio of length to width is 1.0, which means that the slab is a two-way bending one. The steel bar material is HPB300 class, in which the steel bar diameter is $12 \mathrm{~mm}$. The concrete material is C30 class with a cube compressive strength of $30 \mathrm{MPa}$. The concrete cover thickness is $14 \mathrm{~mm}$. The steel bars are layout in two-ways with two layers; the spacing between two bars in $x$ direction is $100 \mathrm{~mm}$ and the spacing in $y$ direction is also $100 \mathrm{~mm}$. The mesh generation of the concrete and steel bar is $20 \mathrm{~mm}$, and between the concrete and steel bar nodes there is onedimensional slide contact. The element type of the concrete chosen is Solid 164, and the steel bar is Beam 161. The numerical model of RC slab is shown in Figure 1.

In order to simulate the support role of the beam to the slab, four rigid beams are set up around the slab and their connections are rigid. The explosive is on the top of slabs. The whole model is shown in Figure 2.

2.2. Material Models. There are many material models to simulate concrete, such as HJC, RHT, and K\&C models [18-22]. However, it is well known that the FE simulation results are very sensitive to the material properties, and thus it is the most important issues to choose the most suitable material model. The $\mathrm{K} \& \mathrm{C}$ model is a three-invariant model and three shear yield faces are used (Figure 3). It can simulate the mechanical behavior of concrete subject to high strain rate and large deformation $[18,19]$ and can simulate some concrete structure behavior under blast loadings in some cases 


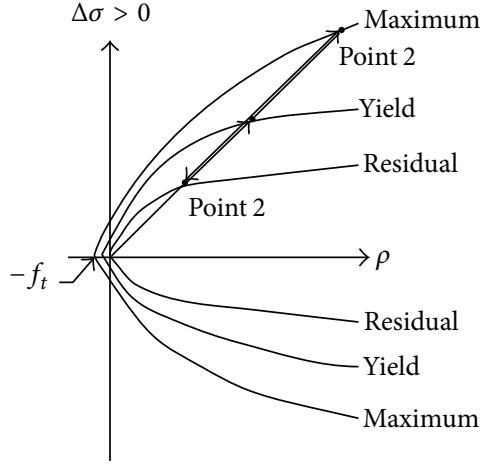

(a)

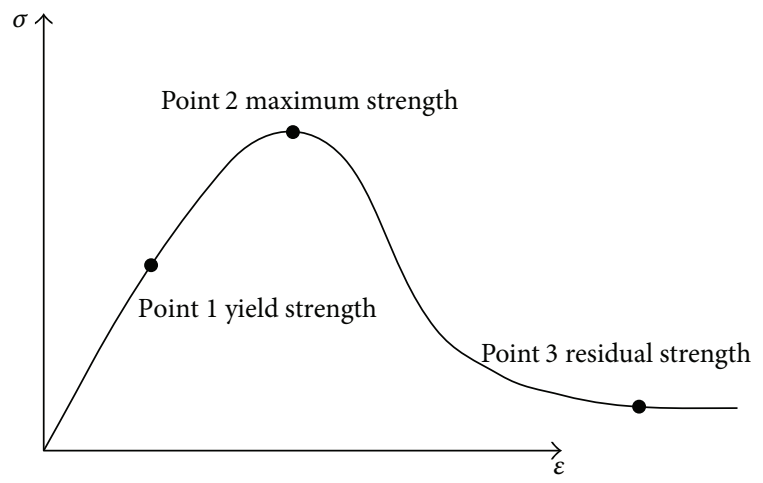

(b)

FIGURE 3: Concrete material model: (a) three strength failure surface and (b) stress-strain curve.

$[15,16,23]$. The advantage of the model is that it needs very few parameters to import in LS-DYNA, and the material type corresponding to K\&C model is Mat_Concrete_Damge_ Rel3 (Mat type 72 rel3). In this study, only the density, uniaxial compressive strength, and Poisson ratio are imported [24, 25]. The density of C 30 concrete is $2500 \mathrm{~kg} / \mathrm{m}^{3}$, uniaxial compressive strength is $20.06 \mathrm{MPa}$, and the Poisson ratio is 0.2 .

Mat-Plastic-Kinematic (Mat type 3) is an isotropic and kinematic hardening plasticity model. The strain rate effect is considered using the Cowper-Symonds model, and the yield stress is defined with the following factor $[24,25]$ :

$$
\sigma_{y}=\left[1+\left(\frac{\dot{\varepsilon}}{C}\right)^{1 / p}\right]\left(\sigma_{0}+\beta E_{p} \varepsilon_{p}^{\mathrm{eff}}\right),
$$

where $\sigma_{0}$ is the yield stress under static loads, $\dot{\varepsilon}$ is the strain rate, $E_{p}$ is the plastic hardening modulus, and $\varepsilon_{p}^{\text {eff }}$ is the effective plastic strain. $C$ and $p$ are the strain rate parameters; in this study, $C=40 \mathrm{~s}^{-1}$ and $p=5$. And $\beta$ is the hardening parameters; when $\beta=0$, it means that the material is kinematic. The density of steel bar is $7800 \mathrm{~kg} / \mathrm{m}^{3}$, the yield stress $\sigma_{0}=300 \mathrm{MPa}$, Young's modulus $E=2.1 \times 10^{5} \mathrm{MPa}$, and Poisson ratio $v=0.3$, respectively.

2.3. Strain-Rate Effects. When the structures are under blast load, it will respond at very high strain rates in the order of $10-$ $1000 \mathrm{~s}^{-1}$ or even higher [26]. Due to the high strain rate, the tensile and compressive ability of concrete will be changed. It needs to consider the strain-rate effects of concrete in a reliable simulation of RC structural dynamic response.

The effect of strain rate on the concrete compressive and tensile strength is typically represented by a parameter, namely, the dynamic increase factor (DIF). It is a ratio of the dynamic-to-static material constants versus strain rate. In this study the dynamic increase factor of compressive strength (CDIF) is adopted, which is recommended by Europe Code CEB [27] and defined as follows:

$$
\begin{aligned}
\mathrm{CDIF} & =\frac{f_{d c}}{f_{c}} \\
& = \begin{cases}\left(\frac{\dot{\varepsilon}}{\dot{\varepsilon}_{\text {stat }}}\right)^{1.026 \alpha} & \text { where } \dot{\varepsilon}_{\text {stat }}<\dot{\varepsilon}<30 \mathrm{~s}^{-1} \\
\gamma\left(\frac{\dot{\varepsilon}}{\dot{\varepsilon}_{\text {stat }}}\right)^{1 / 3} & \text { where } 30 \mathrm{~s}^{-1}<\dot{\varepsilon}<300 \mathrm{~s}^{-1},\end{cases}
\end{aligned}
$$

where $f_{d c}$ and $f_{c}$ are the compressive strength with the dynamic strain rate $\dot{\varepsilon}$ and static strain rate $\dot{\varepsilon}_{\text {stat }}$, respectively. Here, $\dot{\varepsilon}_{\text {stat }}=30 \times 10^{-6} \mathrm{~s}^{-1}, \log \gamma=6.156 \alpha-2$, and $\alpha=\left(5+9 f_{c}\right)$ $10)^{-1}$

The dynamic increase factor of tensile strength (TDIF) is recommended by the corrected value due to Malvar and Ross's work [26]. It is defined as follows:

$$
\text { TDIF }=\frac{f_{d t}}{f_{t}}= \begin{cases}\left(\frac{\dot{\varepsilon}}{\dot{\varepsilon}_{\text {stat }}}\right)^{\delta} & \text { where } \dot{\varepsilon}_{\text {stat }}<\dot{\varepsilon}<1 \mathrm{~s}^{-1} \\ \beta\left(\frac{\dot{\varepsilon}}{\dot{\varepsilon}_{\text {stat }}}\right)^{1 / 3} & \text { where } 1 \mathrm{~s}^{-1}<\dot{\varepsilon}<160 \mathrm{~s}^{-1},\end{cases}
$$

where $\log \beta=6 \delta-2, \delta=1 /\left(1+8 f_{c} / 10\right)$, and $f_{d t}$ and $f_{t}$ are the tensile strength with dynamic strain rate $\dot{\varepsilon}$ and static strain rate $\dot{\varepsilon}_{\text {stat }}$, respectively; here $\dot{\varepsilon}_{\text {stat }}=10^{-6} \mathrm{~s}^{-1}$. The static compressive strength should be $30 \mathrm{MPa}$ to $70 \mathrm{MPa}$. The $\mathrm{CEB}$ concrete material has been applied to numerical simulation by many scholars $[5,6,15,16]$.

2.4. Blast Load. Whatever the explosion happened within or without the structure, the pressure exerting on the slab is not uniform distribution. It depends on the relative location between the explosive and the slab, the periphery structural component distribution, the direction of the shock wave motion, and so on. At the same time, the slab will be subjected to more than one impact by the reflected wave. In this study, the keyword "load_blast" [24] in the software LS-DYNA is used to define the pressure of explosive exerted on the slab, and the pressure is calculated by CONWEP [28].

In CONWEP, it requires a list of the surface segments that will experience the blast loading, the explosive weight, and explosive position. The calculation principle is based on the scale distance in Brode function. The CONWEP algorithms do account for incidence angle by combining the reflected pressure (normal-incidence) value and the incident pressure (side-on incidence) value, and the formula from TM5-1300 


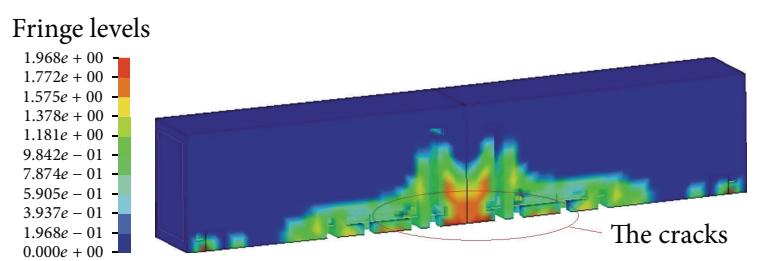

(a)

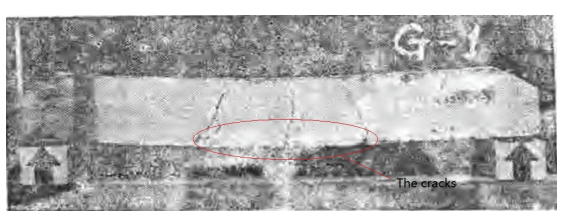

(b)

FIgURE 4: Comparison between FE model (a) and experimental model (b) of structures.

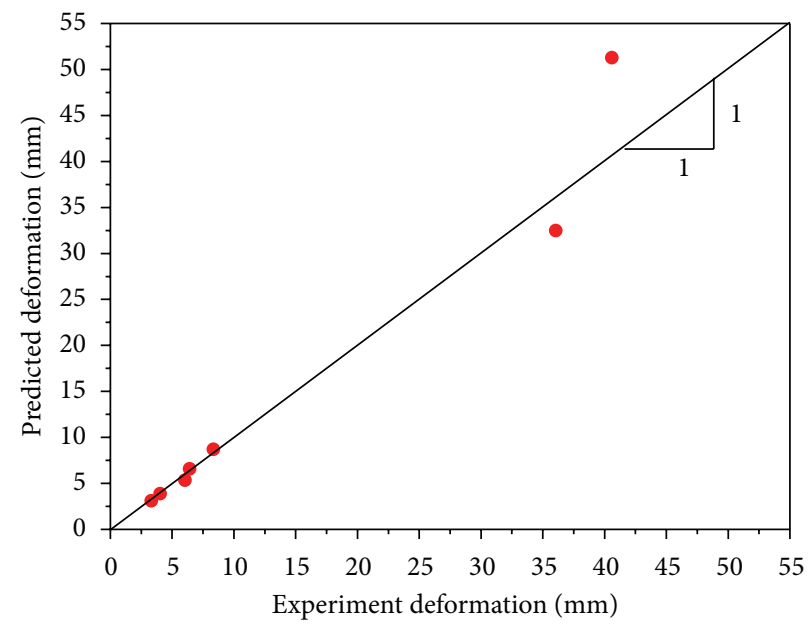

Figure 5: Comparison of experimental and predicted midspan deformations.

[29] is used in the method. The pressure on the structure is given as follows [25]:

$$
P=P_{r} \cos ^{2} \theta+P_{i}\left(1+\cos ^{2} \theta-2 \cos \theta\right)
$$

where $P$ is the pressure exerted on the slab, $P_{i}$ is the incident pressure, $P_{r}$ is the reflected pressure, and $\theta$ is the incidence angle, respectively.

2.5. Validation of Numerical Approach. The dynamic response of RC structure components under blast loadings is tested by Antiknock studio of Tsinghua University [30]. In this study, the RC beam under blast load test is used to validate the proposed modeling method and material model chosen. A typical specimen (beam G1 in references [30]) experimental deformation is compared with the FE prediction. The cracks occurred at the bottom in the midspan area of the beam (Figure 4), and the largest displacement and the reinforcement stress are consistent with the experimental measurements. For the specimen G1, the strain of tensile reinforcement is $2.92 \times 10^{-3}$ in the test and $2.79 \times 10^{-3}$ in the FE calculation, the difference between the test and FE results is only $4.5 \%$, and the tensile reinforcements are all in an elastic stage; The largest displacements in the test and $\mathrm{FE}$ calculation are $3.3 \mathrm{~mm}$ and $3.42 \mathrm{~mm}$; the difference is $3.63 \%$. For the specimen G2, the largest displacement difference is only $3.75 \%$, and the tensile reinforcements are both yield in the test and
FE calculation. The comparison on the predicted results by the FE analysis and the experimental measurements in other cases is plotted in Figure 5. It can be seen that the predicted results by $\mathrm{FE}$ analysis are in good agreement with the experimental observations, particularly for the deformations fewer than $10 \mathrm{~mm}$.

\section{Dynamic Behaviors of RC Slabs Subject to Blast Loadings}

This section presents the dynamic responses and failure modes of RC slabs. The deformation and failure modes under blast loadings are described in Sections 3.1 and 3.2. Also the effects of explosive position (Section 3.3) are considered. Details are presented in the following sections.

3.1. Peak Displacement of Centre Point in Slab. Subjected to blast loadings, the most sensitive factor to the dynamic response of a structure is the peak value of blast loading. When the explosive is exploded in the air, the peak value of blast loading exerted on the slab is defined by the scaled distance. By the Brode function, if the scaled distance increases, the incident pressure will decrease and the reflected pressure will decrease too [31], so the peak value of blast will decrease. The scaled distance is defined as follows:

$$
Z=\frac{H}{\sqrt[3]{W}}
$$


TABLE 1: Maximum displacement of RC slab under different explosive charges.

\begin{tabular}{|c|c|c|c|c|}
\hline Explosive weight $(\mathrm{kg})$ & Distance (m) & $\begin{array}{l}\text { Scaled distance } \\
\qquad\left(\mathrm{m} / \mathrm{kg}^{1 / 3}\right)\end{array}$ & $\begin{array}{c}\text { Peak value of } \\
\text { blast load }(\mathrm{MPa})\end{array}$ & $\begin{array}{l}\text { Maximum } \\
\text { displacement of } \\
\text { centre point } \\
(\mathrm{mm})\end{array}$ \\
\hline 5 & \multirow{6}{*}{5} & 2.92 & 0.23 & 3.46 \\
\hline 10 & & 2.32 & 0.42 & 6.99 \\
\hline 30 & & 1.61 & 1.22 & 19.96 \\
\hline 50 & & 1.35 & 2.03 & 47.21 \\
\hline 75 & & 1.18 & 3.03 & 84.28 \\
\hline 100 & & 1.08 & 4.02 & 158.08 \\
\hline
\end{tabular}

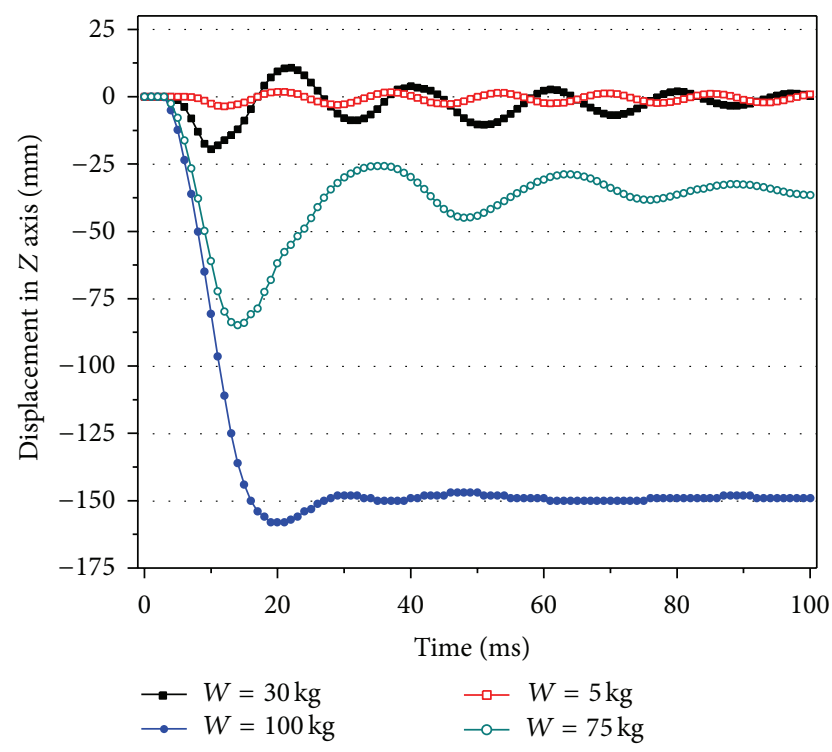

Figure 6: Displacement time history of RC slabs under different explosive weights.

where $Z$ is the scaled distance, $W$ is the explosive weight, and $H$ is the distance between the explosive and the target point [28].

In the simulation, the dynamic response is calculated with blast loadings from different explosive weights, and $H$ is equal to $5.0 \mathrm{~m}$. The results are shown in Table 1 and Figure 6.

It can be seen that the explosion happened in time $t=$ $0 \mathrm{~ms}$, the shockwave achieves the centre point of RC slab at $4 \mathrm{~ms}$, and at the same time the slab starts to vibrate along the shockwave motion direction (the negative direction in $Z$ axis). The displacement of RC slab is negative and achieves the maximum deformation rapidly. After that, the slab vibrates in a high frequency at the equilibrium position. When the explosive weight is smaller (the explosive weight is $5 \mathrm{~kg}$ ), no plastic deformation is occurred in the slab after explosion, and the slab is in a free vibration. When the explosive weight is larger (the explosive weight is larger than $30 \mathrm{~kg}$ ), the plastic deformation is occurred in the RC slab subjected to the blast loadings, and the slab will vibrate at the new equilibrium position. The new equilibrium position is the residual deformation of RC slabs under blast loadings.

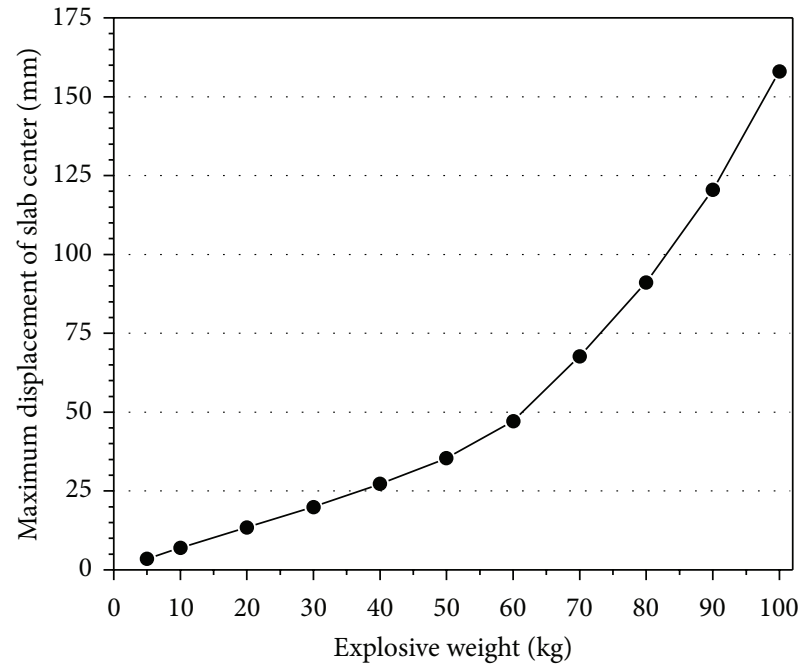

Figure 7: Maximum displacement of RC slabs under different explosive weights.

Figure 7 represents the relationship of maximum displacement and explosive weights. With the increase of explosive weight, the maximum displacement is increased as a curve and the slope is also increased.

3.2. Failure Modes. Subjected to blast loadings, the failure modes of the one-way bending $\mathrm{RC}$ slab are often to be one of the flexural failure, direct shear failure, and flexuralshear failure [2], respectively. The failure modes of two-way bending RC slab are investigated here.

When the explosive weight $W=50 \mathrm{~kg}$, the distance $H=$ $5.0 \mathrm{~m}$, and the scaled distance is $1.35 \mathrm{~m} / \mathrm{kg}^{1 / 3}$, the peak value of blast loading exerted on the slab is $P_{\max }=2.03 \mathrm{MPa}$. The failure mode of RC slab is flexural failure. It shows that the concrete of tensile zone at midspan is destroyed and the steel bar in this zone is yielded, and even for the compressive zone located on the upper region of mid-span, it is also destroyed. The destroyed area is concentrated in the centre of slab as shown in Figure 8(a).

When the explosive weight $W=200 \mathrm{~kg}$, the distance $H=$ $5.0 \mathrm{~m}$, and the scaled distance is $0.85 \mathrm{~m} / \mathrm{kg}^{1 / 3}$, the peak value of blast loading exerted on the slab is $P_{\max }=8.14 \mathrm{MPa}$. The 


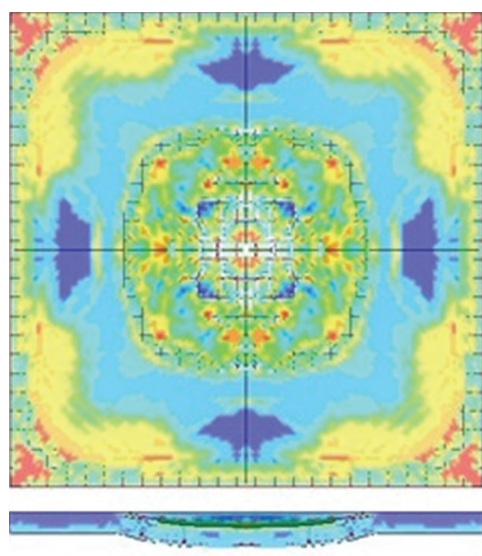

(a)

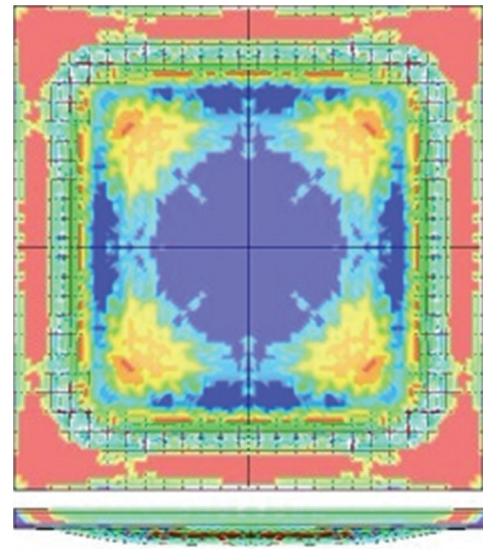

(b)

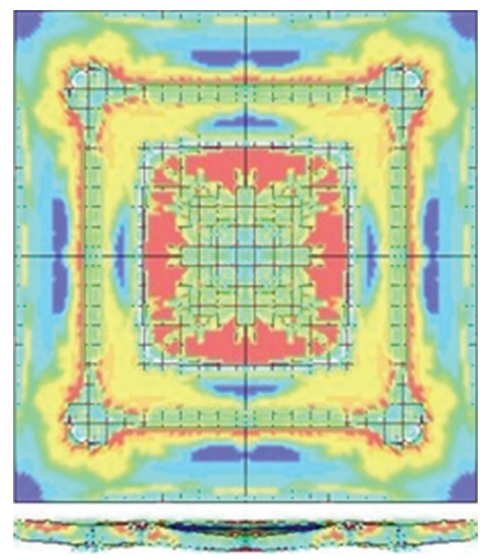

(c)

FIGURE 8: Failure modes: (a) flexural failure, (b) direct-shear failure, and (c) flexural-shear failure.

failure mode of RC slab is direct-shear failure. The reason is that the peak value of the blast loading is at a high level and the duration time is short, and the shear stress at the zone near to the support increased rapidly, so this zone is destroyed. At the same time, the bending deformation did not even occur. The main characteristics of the direct-shear failure mode are the destroyed area concentrated in the regions nearby the boundary as shown in Figure 8(b).
When the explosive weight $W=100 \mathrm{~kg}$, the distance $H=$ $5.0 \mathrm{~m}$, and the scaled distance is $1.08 \mathrm{~m} / \mathrm{kg}^{1 / 3}$, the peak value of blast loading exerted on the slab is $P_{\max }=4.02 \mathrm{MPa}$. The failure mode of RC slab is flexural-shear failure. As the $P_{\max }$ is larger than the load which caused flexural failure and it is smaller than the load which caused direct-shear failure, there are destroyed areas in both the centre and the boundary as shown in Figure 8(c).

The failure mode of RC slab will appear in the form of flexural failure, flexural-shear failure, and direct-shear failure sequentially when the explosive weight is increased.

3.3. Effect of Explosive Position. In the event of an actual explosion, the explosion may not always occur above the centre of slab. It is necessary to study the dynamic response and failure mode when the explosive position is changed. So keeping the explosive weight $W=50 \mathrm{~kg}$ and the distance $H=$ $5.0 \mathrm{~m}$, the scaled distance is $1.35 \mathrm{~m} / \mathrm{kg}^{1 / 3}$, and the peak value of the blast loading exerted on the slab is $P_{\max }=2.03 \mathrm{MPa}$. Then the explosive is moved along the $y$ axis from centre to boundary. Figures 9 and 10 are the maximum displacement of the centre and the stress of steel bar in the slab, respectively.

These figures showed that when the explosive moved from the slab centre to the boundary (the parameter $r$ is the distance from centre to the boundary, $r=0 \sim 1.5 \mathrm{~m}$ ). The maximum displacement of the slab centre is reduced and the stress of the steel bar in tensile zone of slab (in midspan) can be effectively decreased, but the stress of steel bar nearby the boundary is increased. The failure mode changes from flexural failure to the direct-shear failure at the same time. It can be found that although the explosive performance parameters are the same, the failure mode is changed with the explosive position. When the explosive position is moved to the boundary, direct-shear failure may happen easily.

\section{Damage Assessment of RC Slabs Subject to Blast Loadings}

In this section, a new damage assessment criterion is defined and a numerical method to evaluate the damage is proposed in Section 4.1. Then the damage degrees of RC slabs under different explosive cases are evaluated in Section 4.2. Also the effects of negative reinforcement steel bar length and boundary conditions on the antiexplosive ability of RC are analyzed in Section 4.3.

4.1. The Criteria of Damage Assessment. The most common damage index for assessing the damage degree is the midspan displacement of slabs or the support rotation, but it is not very effective to evaluate the damage degree if the failure modes are shear failure or shear-bending failure. It needs new criteria to evaluate the damage degree. The new criteria should be proposed based on the following considerations.

(1) It should be suitable for evaluating damage degree of RC slabs from all failure modes.

(2) It should be related to the global properties of RC slabs. 


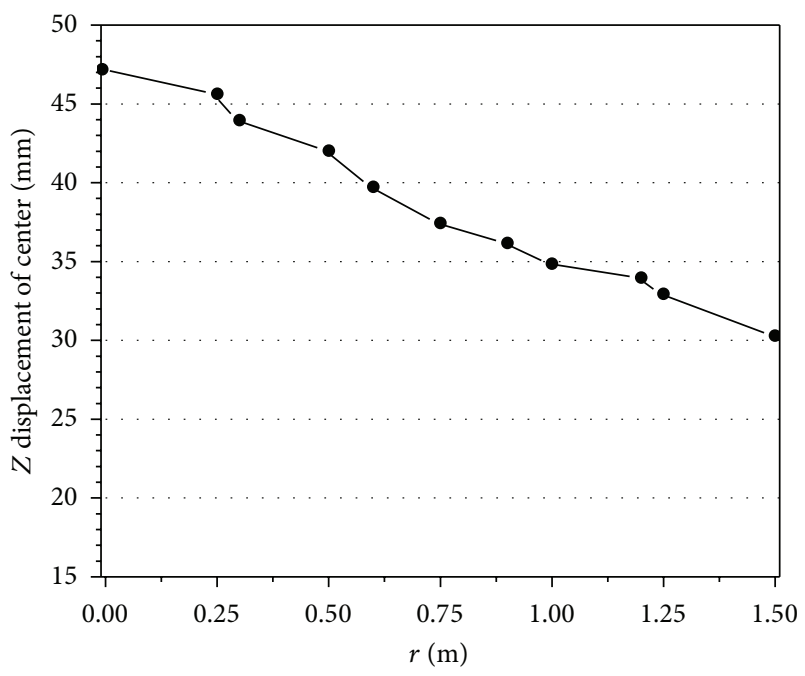

FIgURE 9: Maximum displacement of slab center under different explosive positions.

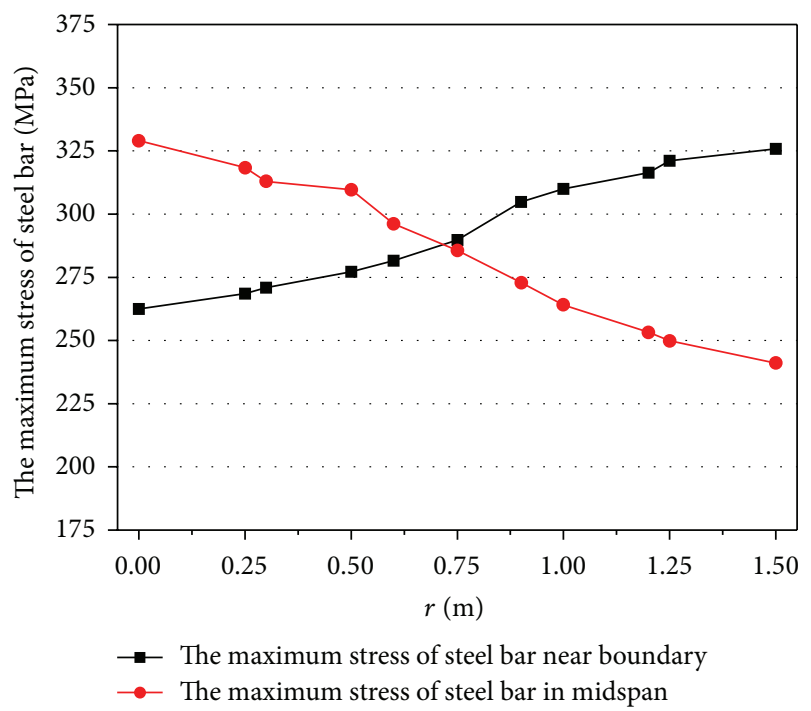

FIGURE 10: Maximum stress of steel bar under different explosive positions.

(3) It should be easily obtained for experiments and numerical simulations.

The slab is the important component which suffers direct load in the frame, so we can make a damage assessment criterion by the uniformly distributed load-carrying capacity of the slab as follows:

$$
\mathrm{DI}=1-\frac{P_{R}}{P_{O}},
$$

where $P_{O}$ is the original load-carrying capacity and $P_{R}$ is the residual load-carrying capacity of the slab. Criteria for the various damage levels can be defined [15] as follows: when $\mathrm{DI}=0 \sim 0.2$, it means that the slab is in a low damage state; $\mathrm{DI}=0.2 \sim 0.5$, medium damage; $\mathrm{DI}=0.5 \sim 0.8$, high damage; and DI $=0.8 \sim 1$, the structure will be collapsed.

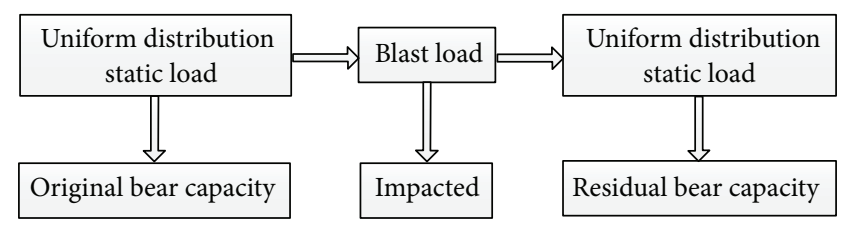

FIGURE 11: Flowchart of damage assessment program.

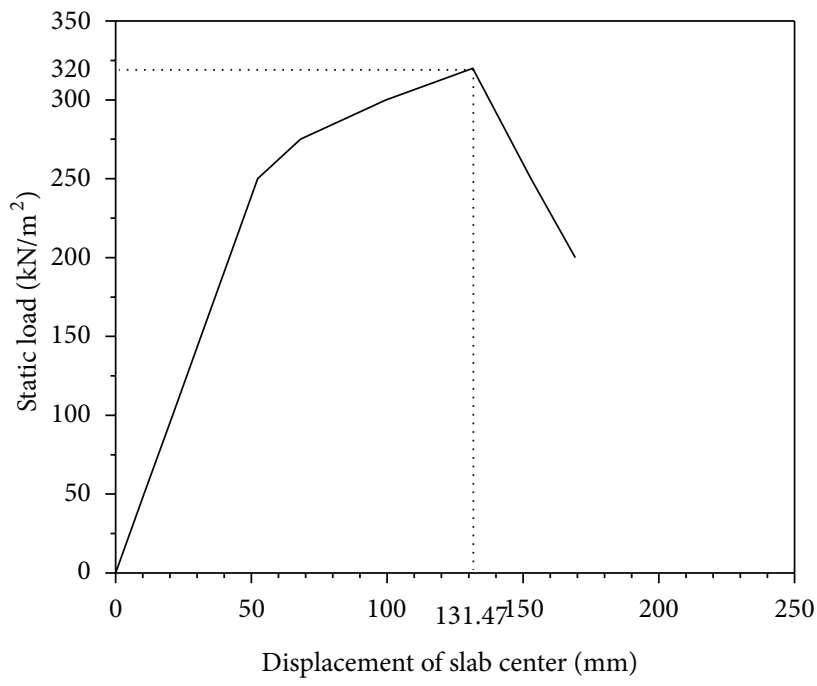

Figure 12: Displacement-static load curve of slab center.

The damage degree of RC two-way bending slab can be obtained by the following steps.

(1) Establishing the finite element model of RC slab and exerting the uniformly distributed load on the slab. The load is increased slowly from 0 until the slab is destroyed. With the load and the midspan displacement curve, we can get the limit load-carrying capacity of uniformly distributed load.

(2) Applying the blast load on the top surface of RC slab and analyzing the dynamic response and damage situation. In order to get the whole response history, it needs a longtime to calculate until the structure gets a new equilibrium state. When the node velocity of the slab reaches $0.1 \mathrm{~m} / \mathrm{s}$, we can stop this step and consider the structure at a static equilibrium status.

(3) Getting the residual load-carrying capacity of the RC slab through the restarted method. Exerting the uniformly distributed load on the slab again and increasing slowly from 0 until the slab is destroyed again after forcing the node velocity to 0 .

(4) Calculating the damage degree by (6). The damage assessment program is shown in Figure 11.

The original load-carrying capacity of RC two-way bending slab is obtained by some numerical simulations. Figure 12 shows the displacement-pressure curve of the slab centre. When the displacement of center point is at range $0 \sim 51 \mathrm{~mm}$, the corresponding pressure value is from $0 \sim 250 \mathrm{kN} / \mathrm{m}^{2}$, the 


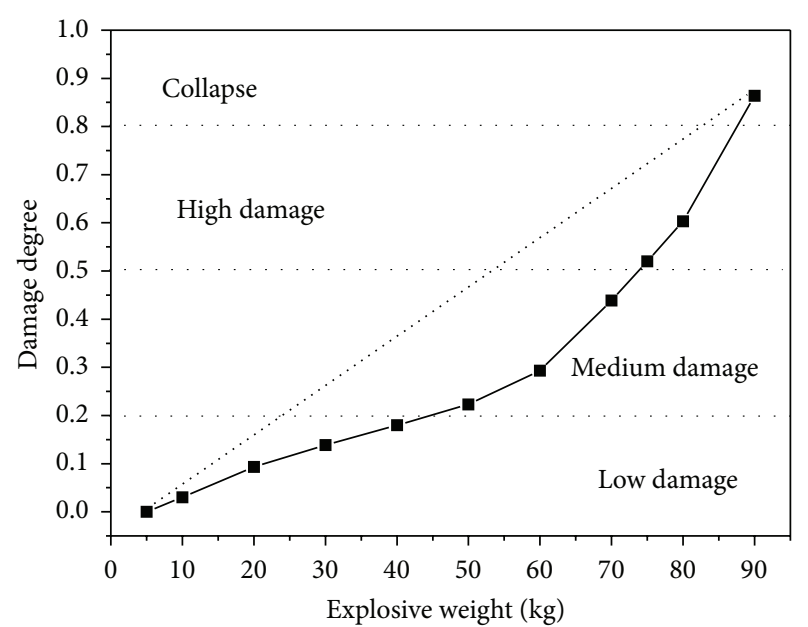

FIGURE 13: Damage degree of RC slabs under different explosive weights.

curve is almost a straight line, and the slab is in an elastic stage. When the displacement is larger than $51 \mathrm{~mm}$, the displacement increases obviously while the pressure has little increase, and the slab is in a plastic stage. When the displacement of slab center is $131.47 \mathrm{~mm}$, the pressure achieves the maximum value. The corresponding original load-carrying capacity $P_{O}$ is $320 \mathrm{kN} / \mathrm{m}^{2}$.

In the same way, the residual load-carrying capacity of the slab is under blast load ( $W=50 \mathrm{~kg}, H=5.0 \mathrm{~m}$ ), that is, $P_{R}$ is $205.1 \mathrm{kN} / \mathrm{m}^{2}$. So DI $=1-P_{R} / P_{O}=1-205.1 / 320=0.36$, and therefore, the damage of the slab is deemed as in a medium damage state.

\subsection{Different Load Cases}

4.2.1. Different Explosive Weight. The damage degrees of RC two-way bending slab under different explosive weights is shown in Figure 13. When the pressure is tiny with explosive weight $W=5 \mathrm{~kg}$, the slab is perfectly intact with the damage degree $\mathrm{DI}=0$. When the explosive weight is $W=10 \sim 40 \mathrm{~kg}$, it is classified as low damage. When $W=50 \sim 70 \mathrm{~kg}$, it is classified as medium damage. When $W=75 \sim 80 \mathrm{~kg}$, it is classified as high damage. When $W=90 \mathrm{~kg}$, the damage degree DI is 0.86 , and the slab will be deemed as "collapsed".

As the transformation law of the maximum displacement, the damage degree of RC slab is increased with explosive weight increases, and the slope of the curve is increasing, too.

4.2.2. Different Explosive Position. From Section 3.3, the failure mode of RC two-way bending slab changes from flexural failure to direct-shear failure as the explosive position is from center to the boundary. Figure 14 shows the relationship of damage degree and explosive position $(W=50 \mathrm{~kg}$ and $H=$ $5.0 \mathrm{~m})$.

When the distance $r \geq 0.5 \mathrm{~m}$, the damage level changed from "medium damage" to "high damage" and the damage degree is increased while the explosive moving to the boundary. The explosion at the corner will cause larger damage.

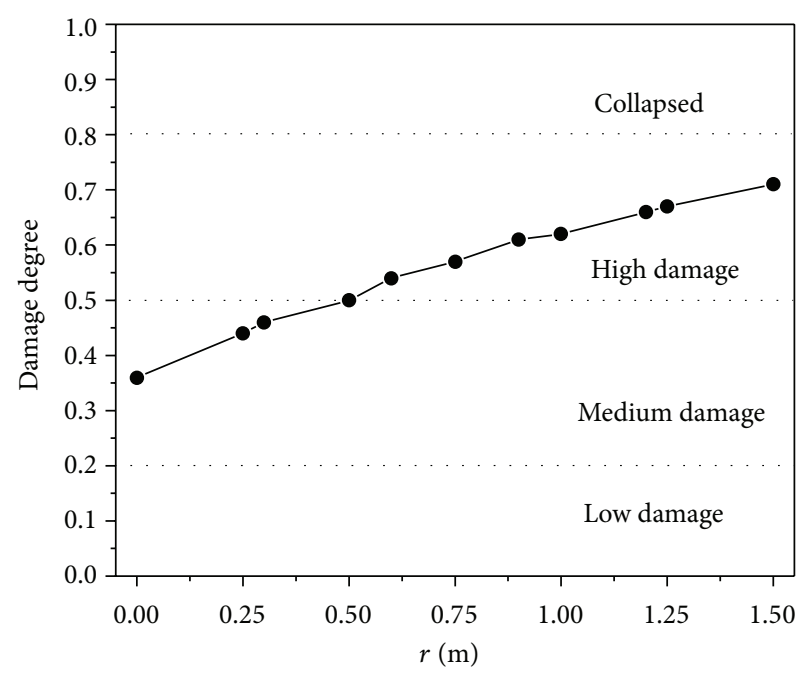

FIGURE 14: Damage degree of RC slabs under different explosive positions.

TABLE 2: Damage degree of RC slab under different reinforcement models.

\begin{tabular}{lccc}
\hline $\begin{array}{l}\text { Length of negative } \\
\text { reinforcement }\end{array}$ & $\begin{array}{l}\text { Original bear } \\
\text { capacity }\left(\mathrm{kN} / \mathrm{m}^{2}\right)\end{array}$ & \multicolumn{2}{c}{$\begin{array}{c}\text { Damage degree } \\
W=30 \mathrm{~kg}\end{array}$} \\
\hline $1 / 4$ & 299 & 0.19 & 0.83 \\
All actual span & 320 & 0.17 & 0.57 \\
\hline
\end{tabular}

Otherwise, if the effects of corners on blast loadings are considered, the damage will be increased.

4.3. Some Design Parameters for Improving the Antiexplosive Ability of RC Slabs. In the two-way bending RC slab design, the boundary conditions will affect the load-carrying capacity directly and the length of negative reinforcement steel bar will affect the seismic design of buildings ability [32]. These parameters may change the antiexplosion ability of the twoway bending RC slab. Based on the above research, we have done some studies on the dynamic response and damage degree of two-way bending RC slab under blast loadings by parameterization analysis.

4.3.1. Length of Negative Reinforcement Steel Bar. As it is defined in the code for design of concrete structures (GB50010-2010) [32], the length of negative reinforcement steel bar from the beam, column, and wall should be at least $1 / 4$ of length of actual span of two-way bending RC slabs for seismic design of buildings.

From Figure 15, when the explosive weight is $W=30 \mathrm{~kg}$, there is no significant difference between the two displacement-time histories of slab center. The maximum displacements have only $10 \%$ change. When the explosive weight is $W=75 \mathrm{~kg}$, the displacement-time history changes a lot. The maximum displacement and residual deformation of the slab are reduced obviously as the length of negative reinforcement is actual span. The damage degree of two-way bending RC 


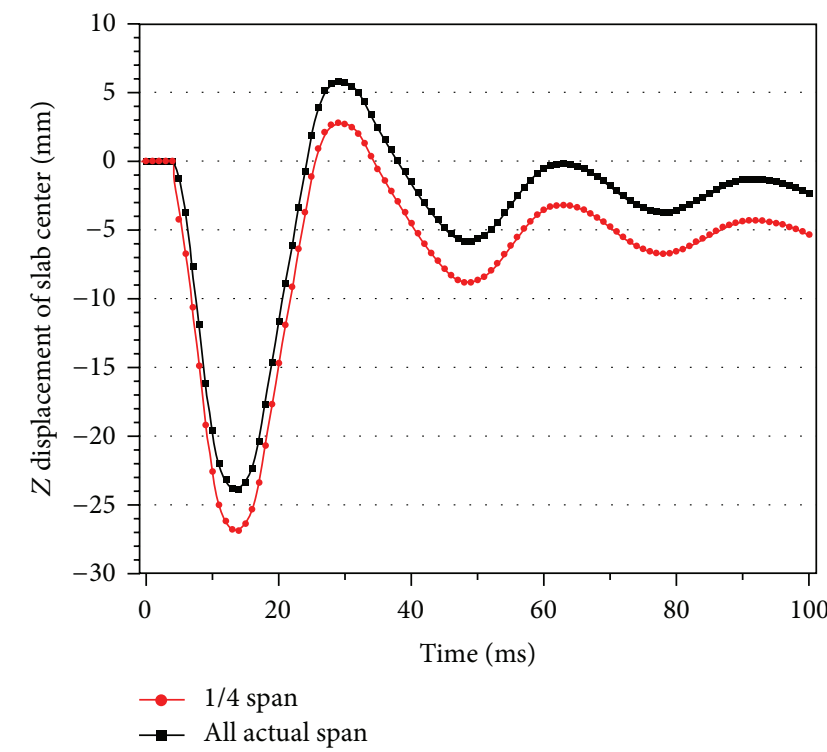

(a)

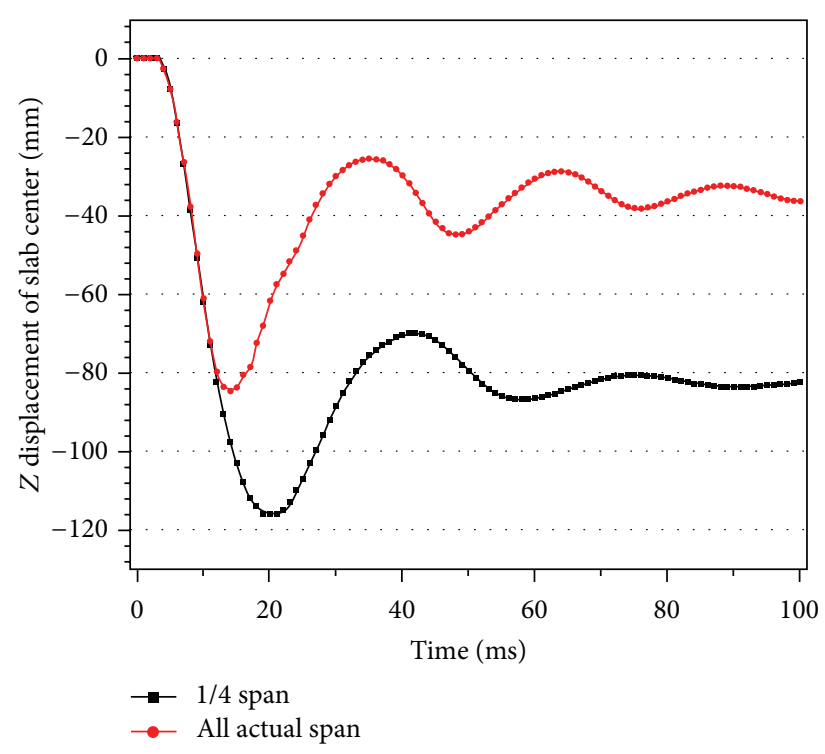

(b)

FIGURE 15: Displacement time histories of RC slab center under different reinforcement types: (a) $W=30 \mathrm{~kg}$ and (b) $W=75 \mathrm{~kg}$.

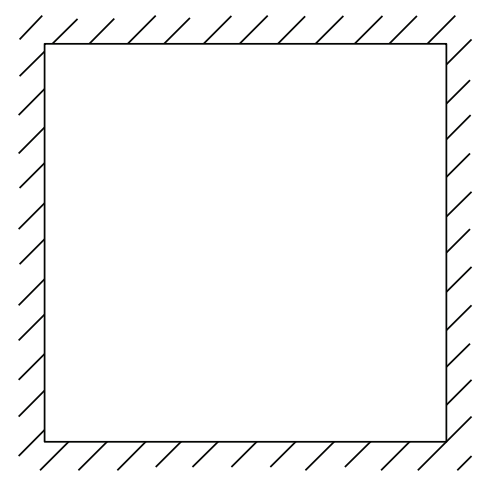

(a)

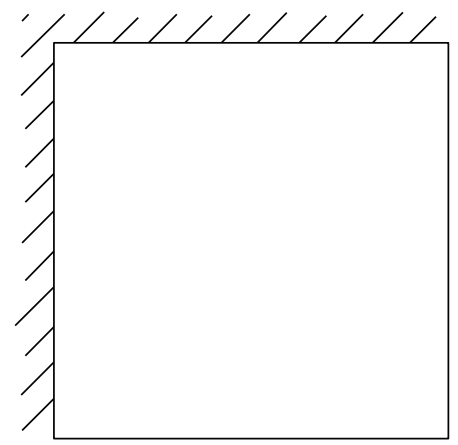

(d)

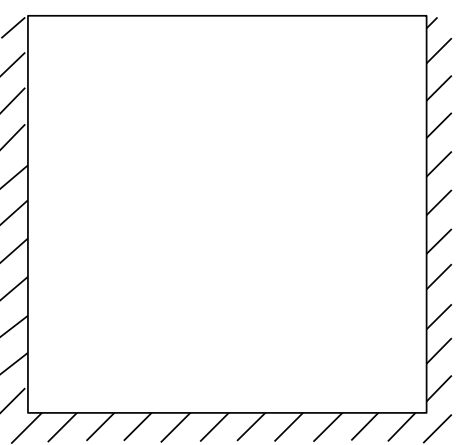

(b)

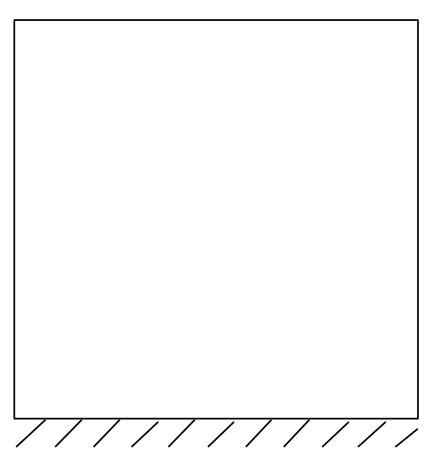

(e)

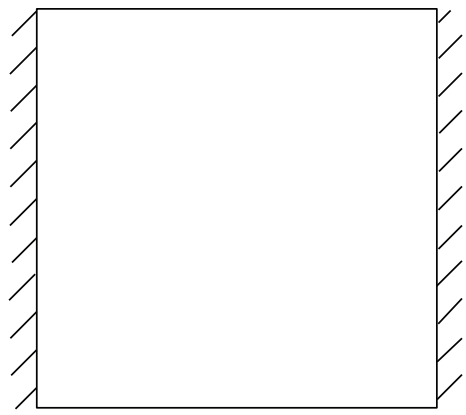

(c)

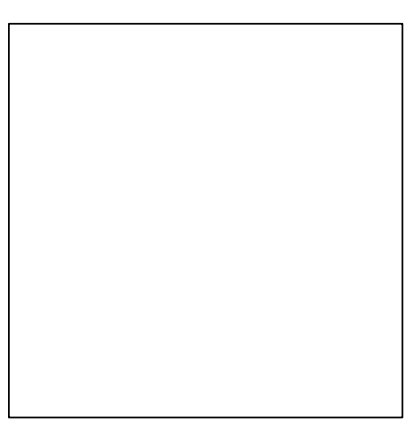

(f)

FIGURE 16: Sketch under different boundary conditions: (a) four edges are clamped, (b) three edges clamped and one edge simply supported, (c) opposite edges clamped and others simply supported, (d) adjacent edges clamped and others simply supported, (e) three edges simply supported and one clamped, and (f) four edges simply supported. 


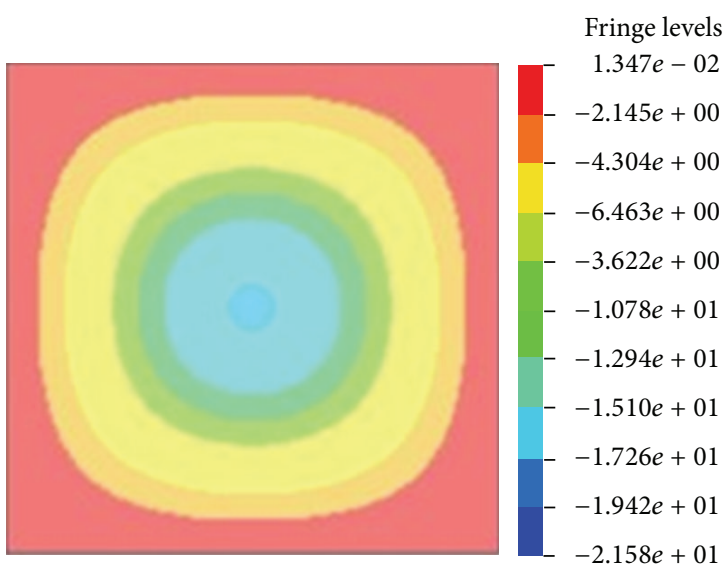

(a)

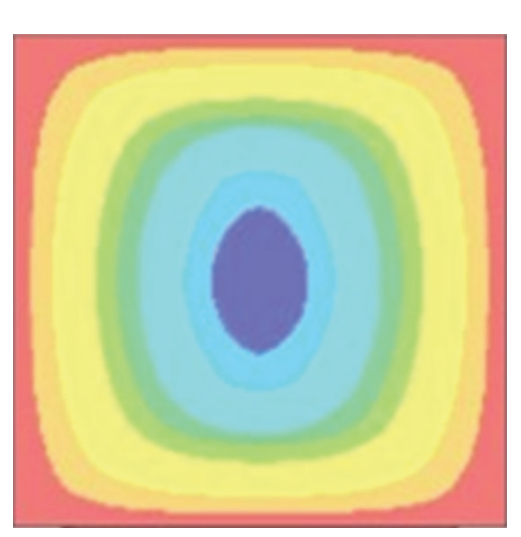

(c)

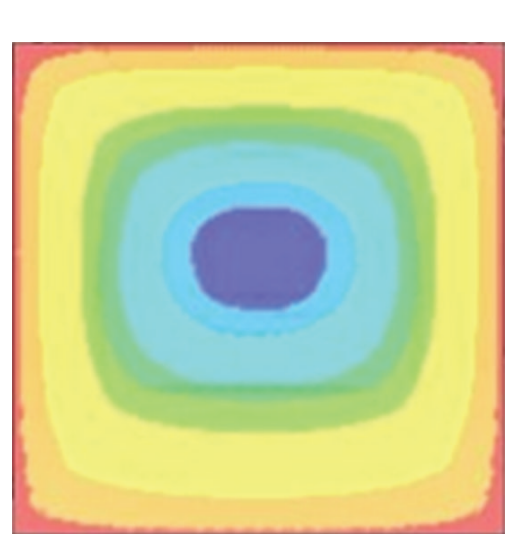

(e)

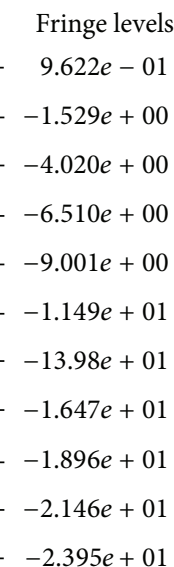

\section{Fringe levels}

$-5.507 e+01$

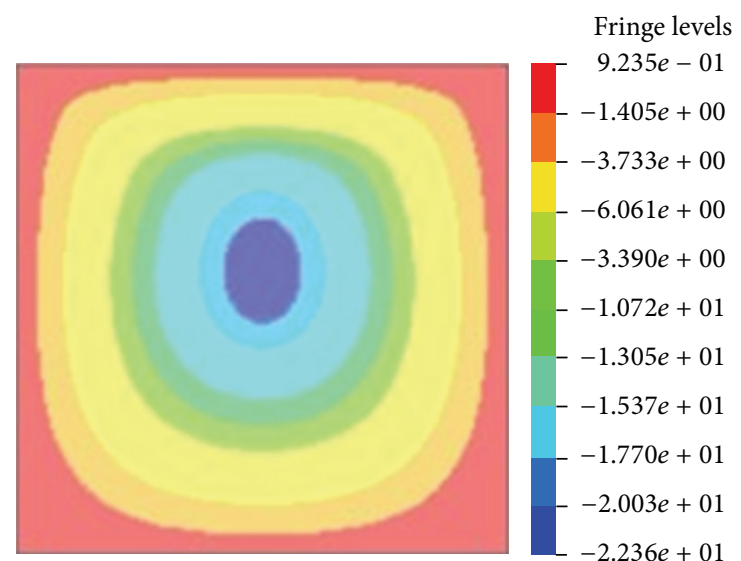

(b)

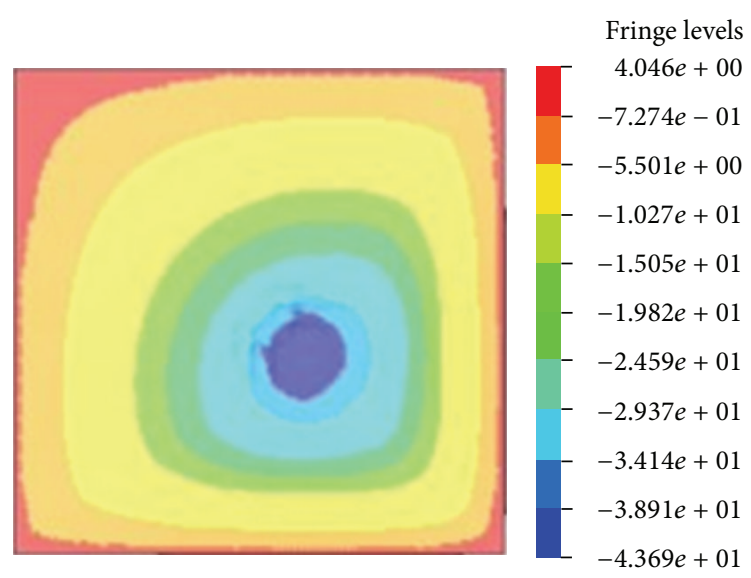

(d)
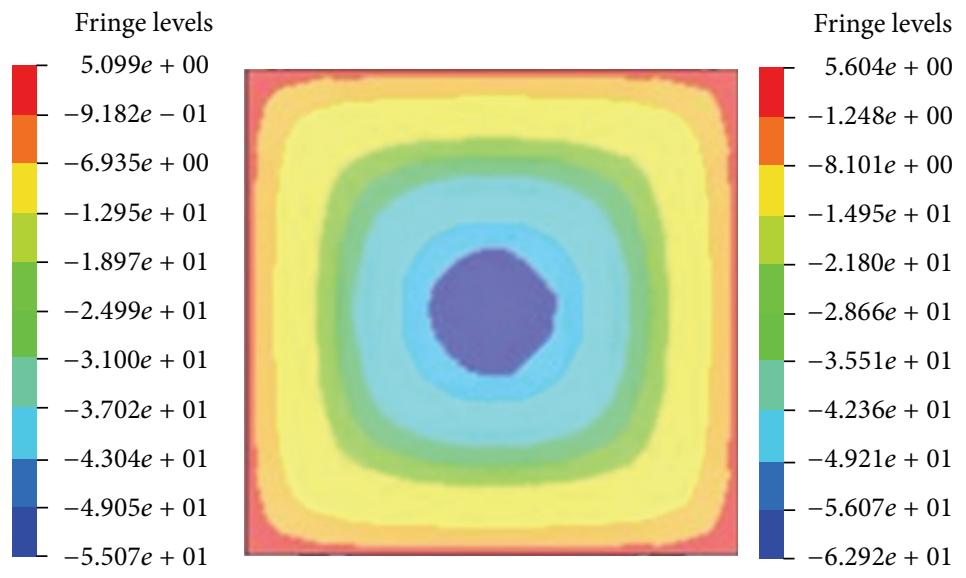

(f)

FiguRE 17: Displacement contours of RC slabs under different boundary conditions.

slabs with different negative reinforcement length is listed in Table 2. The limit load-carry capacities of the slab have not changed so much, and the difference between $1 / 4$ and actual span length of negative reinforcement is only $6 \%$. The damage degree of the slab is 0.19 for $1 / 4$ of length and 0.17 for actual span subject to blast loadings caused by explosive weight $W=$ $30 \mathrm{~kg}$, and the damage states are in the low damage. But for larger explosive weight $W=75 \mathrm{~kg}$, the damage situation changes obviously. The slab with actual span negative reinforcement is in the high damage while the slab with $1 / 4$ of length of span is collapsed; the antiexplosion ability is improved by increasing the length of negative reinforcement. That is because the slab will vibrate up and down under the blast loadings and the bending resistance will increase with 
TABLE 3: Damage degree of RC slab under different boundary conditions.

\begin{tabular}{lcccc}
\hline Boundary condition & Original bear capacity $\left(\mathrm{kN} / \mathrm{m}^{2}\right)$ & Residual bear capacity $\left(\mathrm{kN} / \mathrm{m}^{2}\right)$ & Damage degree & Damage level \\
\hline Case (a) & 320 & 256.6 & 0.17 & Low damage \\
Case (b) & 292 & 226.2 & 0.22 & Medium damage \\
Case (c) & 279 & 193.2 & 0.31 & Medium damage \\
Case (d) & 253 & 142.5 & 0.43 & Medium damage \\
Case (e) & 231 & 96.6 & 0.58 & High damage \\
Case (f) & 197 & 54 & 0.73 & High damage \\
\hline
\end{tabular}

the length of negative reinforcement. So the antiexplosion ability is increased.

4.3.2. Different Boundary Conditions. The actual boundary condition of two-way bending RC slab is between simply and clamped supported, and it can always be treated as simple or clamped supports. The simply supported slab can only pass the force of horizontal and vertical directions, but cannot pass the bending moment. The clamped-supported slab can pass not only the horizontal and vertical force well but also the bending moment. The most common support forms of twoway bending RC slab [32] are supported by four edges as shown in Figure 16. In the numerical simulations, the constraint of RC slab is achieved by changing the support of rigid beam.

In order to analyze the effects of the boundary condition, different boundaries with upper models and the blast case of $W=30 \mathrm{~kg}$ and $H=5.0 \mathrm{~m}$ are used. Figure 17 shows the displacement contours of the moment when the vertical displacement achieves the maximum value. Although the explosive position is over the centre of the slab, the maximum displacements did not appear in the slab centre and the maximum displacement is moved to the simply supported side. The constraint effect is weakening with the increase of the simply supported number, and the maximum displacement of slab centre is increased. It is clear that the antiexplosion ability of two-way bending RC slab will change with the boundary changes.

The damage degrees under different boundary conditions are given in Table 3 . When the four edges are clamped, the damage degree $\mathrm{DI}$ is 0.17 , which is in the low damage. When there are one or two simply supported edges, the damage levels are in the medium damage. When the number of simply supported edges is three or four, the slab is in the high damage. At the same time, the limit load-carrying capacity is reduced with the number increase of simply supported edges.

\section{Conclusions}

In this study, a damage degree assessment criterion is defined based on the residual uniformly distributed load-carrying capacity of a two-way bending RC slab. Using this criterion, the damage degrees of the slab under different explosion cases and design parameters are analyzed. The main results are listed as follows.

(1) The damage degree assessment criterion based on the residual uniformly distributed load-carry capacity presents a new index to evaluate the damage degree of the two-way bending RC slab; it can be applied to all failure modes.

(2) Subjected to blast loadings, the damage degree is directly affected by the explosive weights and positions. The damage degree would increase when the explosive weight is increased or the explosive position is moved from centre to the boundary.

(3) The boundary conditions and the length of negative reinforcement steel bar can directly affect the antiexplosion ability of the slab. For the two-way bending RC slab antiexplosion design, it is better to reduce the number of simply supported edges and layout the negative reinforcement steel bar along the actual span.

\section{Conflict of Interests}

The authors declare that there is no conflict of interests regarding the publication of this paper.

\section{Acknowledgments}

The project is jointly supported by the National Natural Science Foundation of China (51278226 and 11032005) and the Shanxi Natural Science Foundation (2009011036).

\section{References}

[1] T. Ngo, P. Mendis, A. Gupta, and J. Ramsay, "Blast loading and blast effects on structures: an overview," Electronic Journal of Structural Engineering, vol. 7, pp. 76-91, Special Issue: Loading on Structures, 2007.

[2] H. Y. Low and H. Hao, "Reliability analysis of direct shear and flexural failure modes of RC slabs under explosive loading," Engineering Structures, vol. 24, no. 2, pp. 189-198, 2002.

[3] J. Jones, C. Wu, D. J. Oehlers et al., "Finite difference analysis of simply supported RC slabs for blast loadings," Engineering Structures, vol. 31, no. 12, pp. 2825-2832, 2009.

[4] K. Xu and Y. Lu, "Numerical simulation study of spallation in reinforced concrete plates subjected to blast loading," Computers and Structures, vol. 84, no. 5-6, pp. 431-438, 2006.

[5] X. Q. Zhou, V. A. Kuznetsov, H. Hao, and J. Waschl, "Numerical prediction of concrete slab response to blast loading," International Journal of Impact Engineering, vol. 35, no. 10, pp. 11861200, 2008.

[6] X. Zhou, H. Hao, V. A. Kuznetsov, and J. Waschl, "Numerical calculation of concrete slab response to blast loading," Transactions of Tianjin University, vol. 12, pp. 94-99, 2006. 
[7] Y. S. Tai, T. L. Chu, H. T. Hu, and J. Y. Wu, "Dynamic response of a reinforced concrete slab subjected to air blast load," Theoretical and Applied Fracture Mechanics, vol. 56, no. 3, pp. 140-147, 2011.

[8] C. Wu, R. Nurwidayati, and D. J. Oehlers, "Fragmentation from spallation of RC slabs due to airblast loads," International Journal of Impact Engineering, vol. 36, no. 12, pp. 1371-1376, 2009.

[9] A. Schenker, I. Anteby, E. Gal et al., "Full-scale field tests of concrete slabs subjected to blast loads," International Journal of Impact Engineering, vol. 35, no. 3, pp. 184-198, 2008.

[10] S. C. K. Yuen and G. N. Nurick, "Experimental and numerical studies on the response of quadrangular stiffened plates. Part I: subjected to uniform blast load," International Journal of Impact Engineering, vol. 31, no. 1, pp. 55-83, 2005.

[11] G. S. Langdon, S. C. K. Yuen, and G. N. Nurick, "Experimental and numerical studies on the response of quadrangular stiffened plates. Part II: Localised blast loading," International Journal of Impact Engineering, vol. 31, no. 1, pp. 85-111, 2005.

[12] W. Wang, D. Zhang, F. Lu, S. Wang, and F. Tang, "Experimental study and numerical simulation of the damage mode of a square reinforced concrete slab under close-in explosion," Engineering Failure Analysis, vol. 27, pp. 41-51, 2013.

[13] W. Wang, D. Zhang, F. Lu, S. Wang, and F. Tang, "Experimental study on scaling the explosion resistance of a one-way square reinforced concrete slab under a close-in blast loading," International Journal of Impact Engineering, vol. 49, pp. 158-164, 2012.

[14] P. F. Silva and B. Lu, "Blast resistance capacity of reinforced concrete slabs," Journal of Structural Engineering, vol. 135, no. 6, pp. 708-716, 2009.

[15] Y. Shi, H. Hao, and Z. Li, "Numerical derivation of pressureimpulse diagrams for prediction of RC column damage to blast loads," International Journal of Impact Engineering, vol. 35, no. 11, pp. 1213-1227, 2008.

[16] K. Wu, B. Li, and K. Tsai, "Residual axial compression capacity of localized blast-damaged RC columns," International Journal of Impact Engineering, vol. 38, no. 1, pp. 29-40, 2011.

[17] S. Hentz, F. V. Donzé, and L. Daudeville, "Discrete element modelling of concrete submitted to dynamic loading at high strain rates," Computers and Structures, vol. 82, no. 29-30, pp. 2509-2524, 2004.

[18] L. J. Malvar, J. E. Crawford, J. W. Wesevich, and D. Simons, "A plasticity concrete material model for DYNA3D," International Journal of Impact Engineering, vol. 19, no. 9-10, pp. 847-873, 1997.

[19] L. J. Malyar and D. Simons, "Concrete materials modeling in explicit computations," in Workshop on Recent Advances in Computational Structural Dynamics and High Performance Computing, pp. 165-194, USAE Waterways Experiment Station, Vicksburg, Miss, USA, 1996.

[20] T. J. Holmquist, G. R. Johnson, and W. H. Cook, "A computational constitutive mode for concrete subjected to large strains, high strain rates, and high pressures," in Proceedings of the 14th International Symposium on Ballistics, pp. 591-600, Quebec City, Canada, 1991.

[21] G. R. Johnson, S. R. Beissel, T. J. Holmquist, and D. J. Frew, "Computed radial stresses in a concrete target penetrated by a steel projectile," in Proceedings of the 5th International Conference on Structures Under Shock and Impact, pp. 793-806, June 1998.

[22] Z. G. Tu and Y. Lu, "Evaluation of typical concrete material models used in hydrocodes for high dynamic response simulations," International Journal of Impact Engineering, vol. 36, no. 1, pp. 132-146, 2009.
[23] X. Bao and B. Li, "Residual strength of blast damaged reinforced concrete columns," International Journal of Impact Engineering, vol. 37, no. 3, pp. 295-308, 2010.

[24] Livermor Software Technology Corporation, LS-DYNA Keyword User's Manual, Version 971, 2007.

[25] Livermor Software Technology Corporation, LS-DYNA Theory Manual, 2006.

[26] L. J. Malvar and C. A. Ross, "Review of strain rate effects for concrete in tension," ACI Materials Journal, vol. 95, no. 6, pp. 735-739, 1998.

[27] CEB-FIP Model Code 1990, Design Code, Comite EuroInternational Du Beton, UK, 1990.

[28] G. Randers-Pehrson and K. A. Bannister, "Airblast loading model for DYNA2D and DYNA3D," Tech. Rep. ARL-TR-1310, Army Research Laboratory, 1997.

[29] TM5-1300, Structures to Resist the Effects of Accidental Explosions, US Army, 1990.

[30] Antiknock Studio of Tsinghua University, Performance of Reinforced Concrete Structures under Impact Loading, Tsinghua University Press, Beijing, China, 1986.

[31] J. Henrych, The Dynamics of Explosion and Its Use, Elsevier, Amsterdam, The Netherlands, 1979.

[32] GB50010-2010, Concrete Structure Design Code, Ministry of Housing and Urban-Rural, Beijing, China, 2010. 

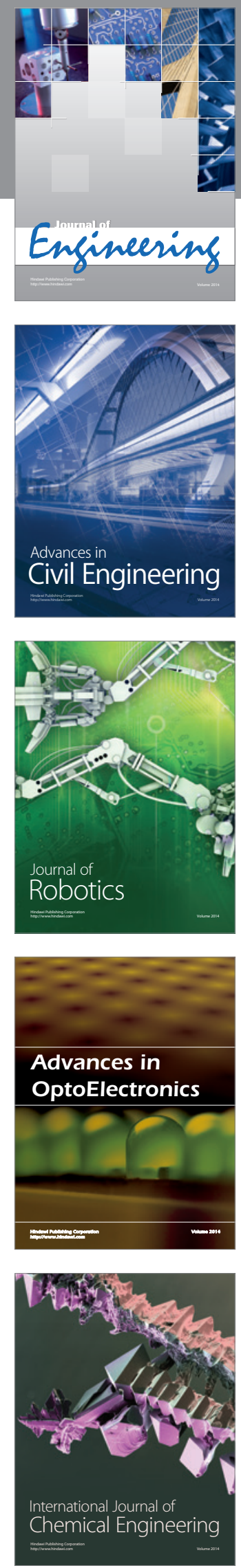

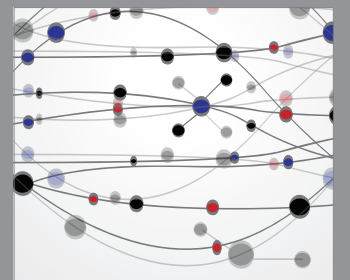

The Scientific World Journal
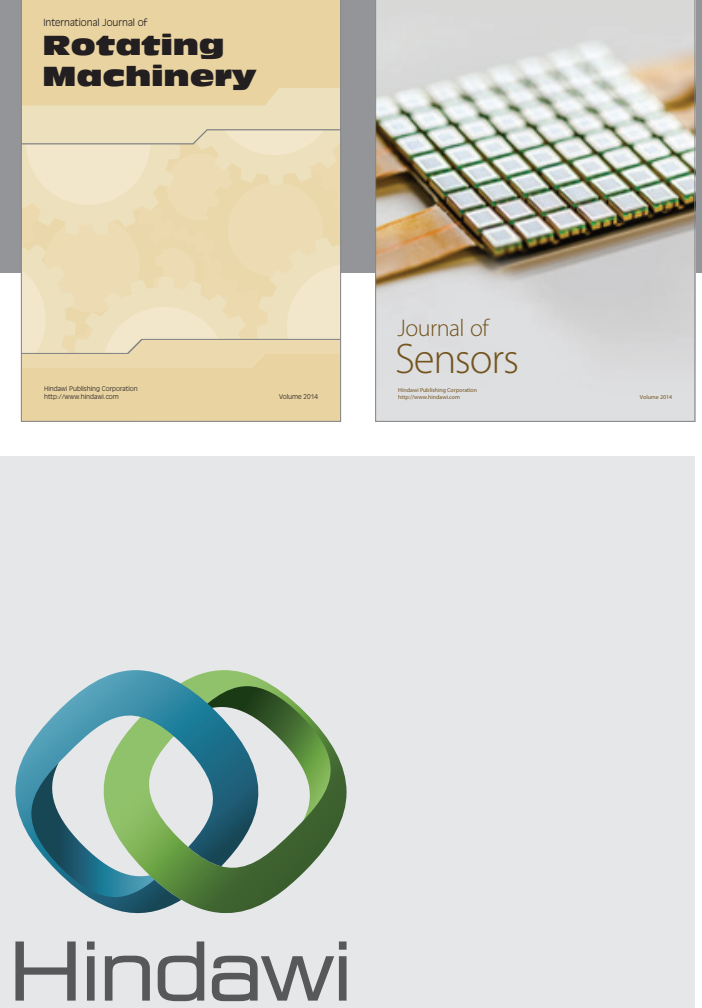

Submit your manuscripts at http://www.hindawi.com
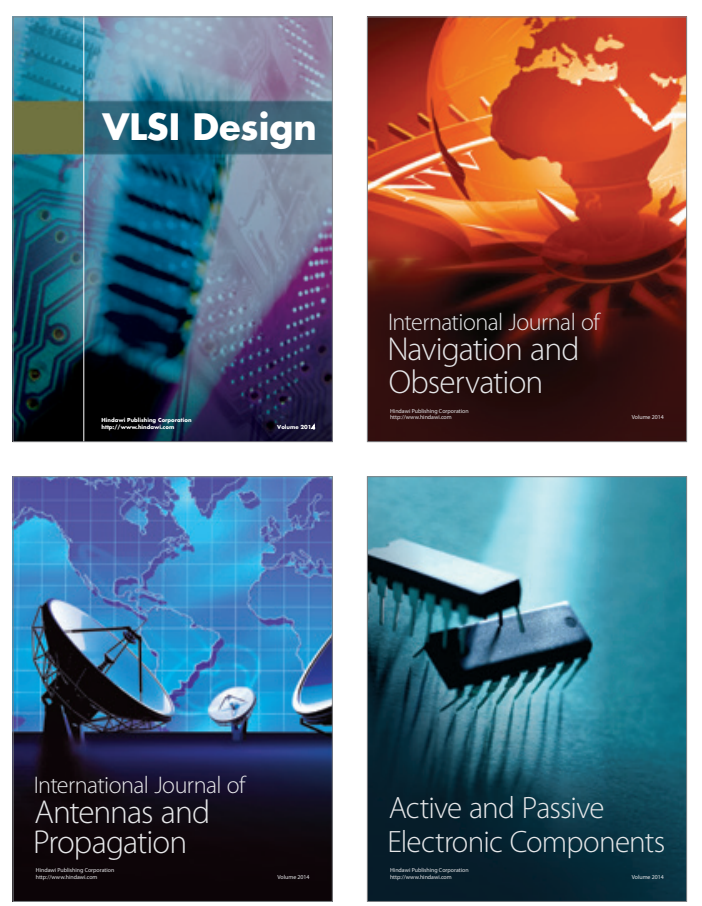
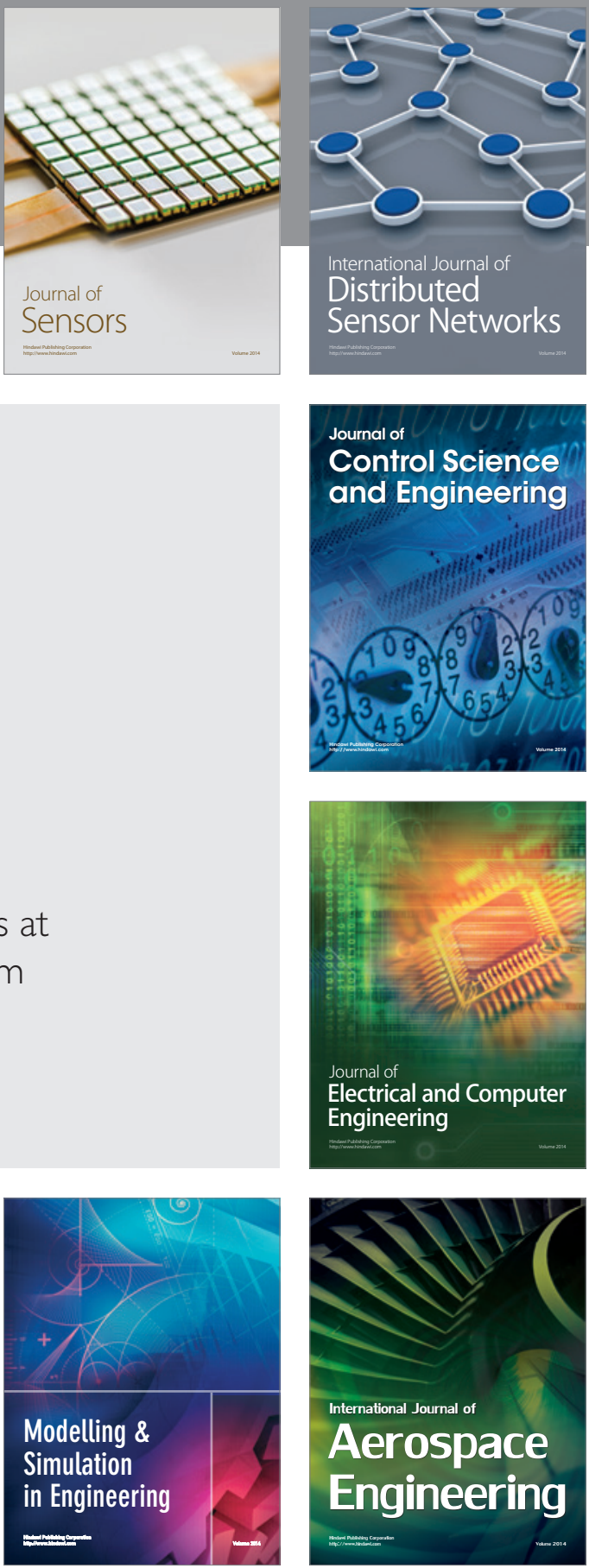

Journal of

Control Science

and Engineering
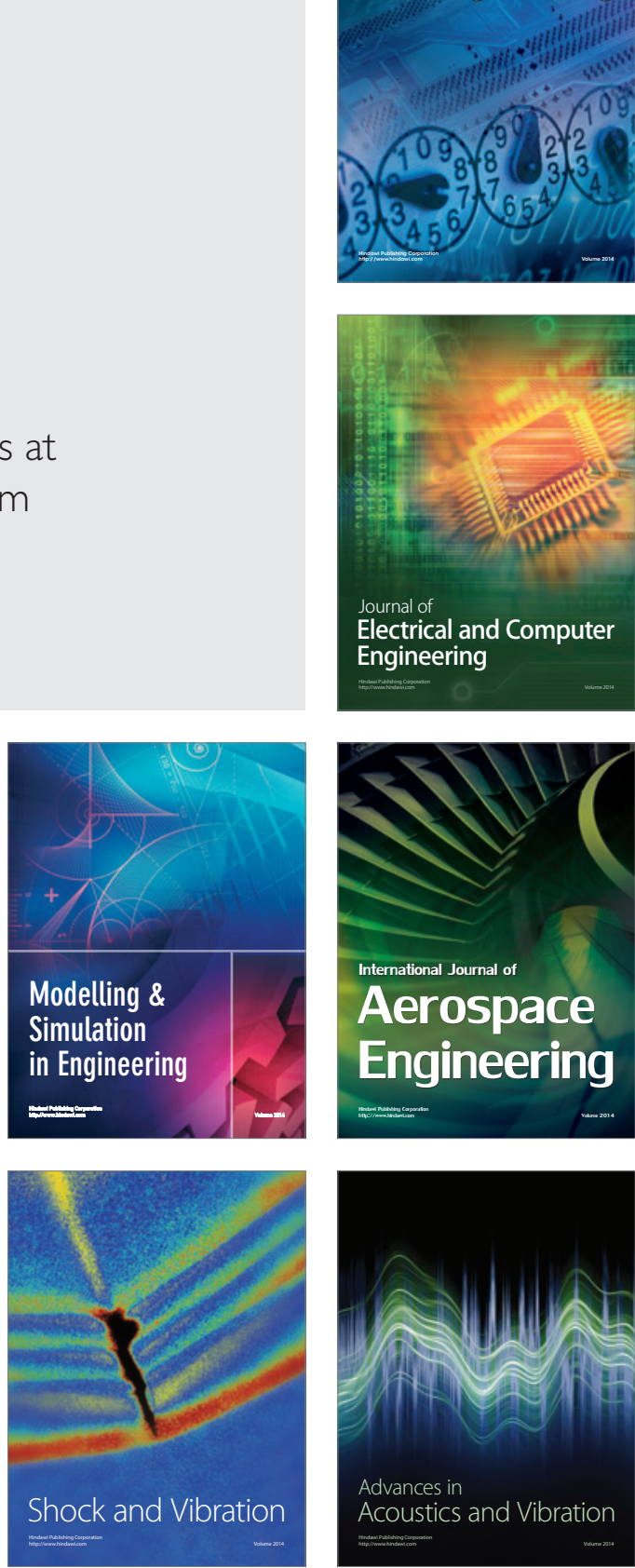